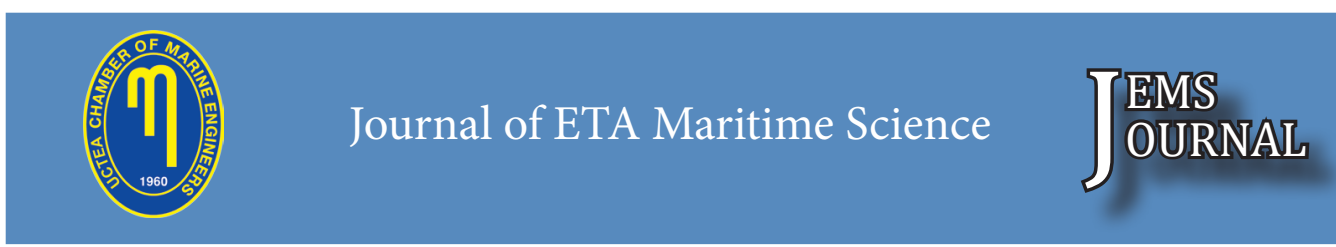

Corresponding Author: Şakir BAL

\title{
Numerical Investigation of Propeller Skew Effect on Cavitation
}

\section{Şakir BAL}

Istanbul Technical University, Naval Architecture \& Ocean Eng. Faculty, Turkey

sbal@itu.edu.tr; ORCID ID: https://orcid.org/0000-0001-8688-8482

\begin{abstract}
This paper addresses the skew effects (a significant geometric property) of marine propellers on cavitation phenomenon numerically. DTMB 4381, 4382, 4383 and 4384 model propellers with different skew values have been chosen to investigate the cavity patterns on the blades under open water conditions. A lifting surface method has been applied for both non-cavitating and cavitating propellers. Numerical results (nondimensional thrust and torque coefficients, efficiency values and cavity patterns on the blades) have been validated with experimental results. It has been found that the present numerical method is accurate and reliable for predicting the hydrodynamic performance of both non-cavitating and cavitating propeller under open water conditions. It has also been found that under certain conditions the skewed blades of the propeller can cause lesser cavity patterns and improve the propeller performance.
\end{abstract}

Keywords: Cavitation, Propeller, Skew, Lifting Surface Method.

\section{Pervane Çalıklığının Kavitasyon Üzerine Etkisinin Sayısal İncelenmesi}

\section{$\ddot{O} z$}

Bu çalışmada, gemi pervanelerinin önemli bir geometrik özelliği olan çalıklığın kavitasyon oluşumu üzerindeki etkileri sayısal olarak incelenmiştir. Bunun için farklı çalıklık değerlerine sahip DTMB 4381, 4382, 4383 ve 4384 model pervaneleri seçilmiş ve açık su şartları altında kanatlar üzerindeki kavitasyon oluşumları hesaplanmıştır. Bir kaldırıcı yüzey yöntemi hem kavitasyon yapan hem de yapmayan pervaneler için uygulanmıştır. Öncelikle, elde edilen sayısal sonuçlar (boyutsuz itme ve tork, verim değerleri ve kanatlar üzerindeki kavitasyon oluşumları) deneysel sonuçlarla doğrulanmıștır. Böylece mevcut yöntemin açık su şartları altında hem kavitasyonlu durumda hem de kavitasyonsuz durumda güvenilirliği ve doğruluğu gösterilmiştir. Çalışma neticesinde belirli şartlar altında artan çalıklık miktarının pervane kanatları üzerinde daha az kavitasyon oluşumuna sebep olacağı ve pervane hidrodinamik performansını iyileștirebileceği bulunmuştur.

Anahtar Kelimeler: Kavitasyon, Pervane, Çalıklık, Kaldırıcı Yüzey Yöntemi. 


\section{Introduction}

It is difficult to avoid the cavitation on propeller blades of modern surface marine vehicles due to the increase of loading. It is well-known that the cavitation can cause vibration, noise, erosion on blades and reduction in efficiency which will eventually deteriorate the functionality and performance of marine vehicles. The skewed propeller can delay or reduce the cavitation amount under certain conditions and improve propeller performance.

In the past, the effects of skew have been studied by various researchers. In [1], the cavitation on a highly skewed propeller DTMB 4384 has been investigated by a RANS (Reynolds-Averaged Navier-Stokes) simulation. The computational results have been validated with experiments. It has been reported that an increase in skew angle is effective to avoid cavitation. In another study [2], unsteady RANS and Bubble Dynamics equations were coupled to predict the cavitation on propeller blades. It was noted that the proper increase in blade skew angle may reduce the cavitation pattern and improve the hydrodynamic performance of the propeller. In [3], the cavitating flows around a highly skewed model propeller under both uniform and non-uniform wake conditions were modelled by applying a mass transfer cavitation technique. This technique used the Rayleigh-Plesset equation and k- $\omega$ turbulence model. It was noted in the study that sheet cavitation as well as tip vortex cavitation that was observed in tests, were regenerated around the flows of highly skewed cavitating propellers. In addition, the relationship between the skew angle and propeller trailing (vortex) wake was numerically investigated in [4] and several model propellers with different skew angles were used in this study. Numerical simulations were based on RANS method. It was found that the contraction of trailing (vortex) wake can be limited with an increase in skew angle and loading conditions. The interaction between cavitating patterns and propeller skew was also examined numerically by using different skewed propellers in [5]. RANS solver was again applied to predict cavitation pattern and pressure values in propeller wake. It was found that under certain operating conditions for high blade loading, sheet cavitation becomes weak with an increase in propeller skew angle. A boundary element method was, on the other hand, applied to examine the skew effect on propeller performance in [6]. But no cavitation analyses were included in the calculations. Effects of advance ratio on the wake evolutions for skewed propeller were investigated numerically in [7]. The skew effect was also analyzed numerically for just one advance ratio in [8]. However, in these studies, RANS simulations applied generally and these studies have not considered a systematic investigation of skew on cavitation.

On the other hand, a lifting surface method for the analysis of unsteady flows around marine propellers working under non-uniform inflow conditions was introduced in [9]. An extended version of this method later was developed for cavitating propellers in [10]. A search algorithm for cavity detachment for back and mid-chord cavitation was also added in the method [11]. Lifting surface method was later improved by taking into account of viscous effects and of a technique for cavitation inception [12]. The viscous effects were assumed to be dominant near the leading edge of the blade sections. Later, a numerical method based on [12] was developed in [13]. This method improved significantly the cavitation simulation on the blades of the propeller [13]. A simpler method based on a lifting line model to compute the propeller hydrodynamic performance was also later introduced in [14]. This method was applied to investigate 
the podded propulsors, too in [15]. A lifting surface method similar to the present study was used to analyze both non-cavitating and cavitating optimized propellers under open water conditions $[16,17]$. It is well-known that a lifting surface method is cost-effective, simpler and faster than RANS solutions.

In the present study, a very fast and reliable lifting surface method similar to the one used in [16] has been selected to analyze the cavitating and non-cavitating propeller with skew. The influence of skew angle on cavitation and hydrodynamic performance of propeller has been discussed under open water conditions.

\section{Numerical Method}

A lifting surface method is applied to calculate the hydrodynamic performance of cavitating propellers as similar to the one given in [17]. The method is summarized here for the completeness of the paper. The lifting surface method models unsteady cavitating flow around a marine propeller. The method assumes an incompressible and irrotational flow around a cavitating marine propeller. There are finite numbers of vortices and sources distributed on the blade camber surface and its wake surface. The strengths of source distribution are calculated by using the thickness distribution in the chord-wise direction. They are independent of time as also given in [18]. Moreover, the unknown strengths of bound vortices on the blade surface can be determined by applying the kinematic boundary condition.

The dynamic boundary condition that is based on Bernoulli's equation requires that the pressure must be equal to the vapor pressure of water on the cavity surface. A searching mechanism is applied her for the unknown cavity extent and length in the direction of each spanwise strip. The cavity thickness, area, and volume can then be found by using the integration technique of the cavity source distribution along each strip. A time domain approach is also used to solve the problem. Each time increment represents an angular position of rotation of the propeller. A uniform frictional drag coefficient is also assumed to calculate the viscous forces.

When the propeller is working under steady flow conditions, the loading on all blades is the same. Hence, the total force and torque of the propeller are calculated by multiplying each blade force and torque by the number of blades. Hub effects can also be included in the calculations by the method of images. The other details of the lifting surface method applied here for propeller analysis are given in [16] and [19].

\section{Validation and Numerical Results}

For a systematic analysis of skew effect, DTMB 4381, 4382, 4383 and 4384 model propellers have been selected since the cavitation and open water results were presented for these series of skewed propellers in $[20,21]$. The main dimensions of the propellers 4381, 4382, 4383 and 4384 , which are taken from [20, 22] are given in Table 1 , Table 2 , Table 3 and Table 4, respectively. Each propeller has a diameter of $30.48 \mathrm{~cm}$, five blades, BAR (Blade Area Ratio) $=\mathrm{A}_{\mathrm{E}} / \mathrm{A}_{0}=0.725$, and NACA a=0.8 camber lines with 66 modified thickness sections. They have similar chord and thickness distributions. The series has maximum projected skew angles $0^{\circ}$ (4381), $36^{\circ}$ (4382), $72^{\circ}$ (4383) and $108^{\circ}$ (4383) at the propeller tip. The geometry and panels used in this study are also shown in Figure 1.

First, the lifting surface method is applied to non-cavitating DTMB 4381, 4382, 4383 and 4384 propellers for validation. The number of vortex 
elements is $(\mathrm{N}=20)$ in the chord-wise direction and $(\mathrm{M}=30)$ in the radius direction of blades. These number of panels have been found to get converged results after some numerical tests. The frictional drag coefficient was assumed to be $\mathrm{C}_{\mathrm{f}}=0.0035$ in the calculations. The thrust and torque coefficients $\left(\mathrm{K}_{\mathrm{T}}\right.$ and $\mathrm{KQ})$ and efficiency value $\left[\eta=(\mathrm{J} / 2 \Pi) *\left(\mathrm{~K}_{\mathrm{T}}\right)\right.$ $\left.\mathrm{K}_{\mathrm{Q}}\right)$ ] of four propellers $(4381,4382,4383$ and 4384) versus advance coefficients (J)

Table 1. Main Dimensions of DTMB 4381 Propeller

\begin{tabular}{|l|l|l|l|l|l|l|}
\hline $\mathrm{r} / \mathrm{R}$ & $\mathrm{c} / \mathrm{D}$ & $\mathrm{P} / \mathrm{D}$ & $\begin{array}{l}\text { Skew } \\
{ }^{0} \mathrm{~J}\end{array}$ & $\mathrm{Rk} / \mathrm{D}$ & $\mathrm{t}_{\max } / \mathrm{D}$ & $\mathrm{f}_{\max } / \mathrm{c}$ \\
\hline 0.2 & 0.174 & 1.332 & 0 & 0 & 0.0434 & 0.0351 \\
\hline 0.25 & 0.202 & 1.338 & 0 & 0 & 0.0396 & 0.0369 \\
\hline 0.3 & 0.229 & 1.345 & 0 & 0 & 0.0358 & 0.0368 \\
\hline 0.4 & 0.275 & 1.358 & 0 & 0 & 0.0294 & 0.0348 \\
\hline 0.5 & 0.312 & 1.336 & 0 & 0 & 0.0240 & 0.0307 \\
\hline 0.6 & 0.337 & 1.280 & 0 & 0 & 0.0191 & 0.0245 \\
\hline 0.7 & 0.347 & 1.210 & 0 & 0 & 0.0146 & 0.0191 \\
\hline 0.8 & 0.334 & 1.137 & 0 & 0 & 0.0105 & 0.0148 \\
\hline 0.9 & 0.280 & 1.066 & 0 & 0 & 0.0067 & 0.0123 \\
\hline 0.95 & 0.210 & 1.031 & 0 & 0 & 0.0048 & 0.0128 \\
\hline 1.0 & 0.000 & 0.995 & 0 & 0 & 0.0029 & 0.0000 \\
\hline
\end{tabular}

Table 2. Main Dimensions of DTMB 4382 Propeller

\begin{tabular}{|l|l|l|l|l|l|l|}
\hline $\mathrm{r} / \mathrm{R}$ & $\mathrm{c} / \mathrm{D}$ & $\mathrm{P} / \mathrm{D}$ & $\begin{array}{l}\text { Skew } \\
\mathrm{C}^{0} \mathrm{Rk} / \mathrm{D}\end{array}$ & $\mathrm{t}_{\max } / \mathrm{D}$ & $\mathrm{f}_{\max } / \mathrm{c}$ \\
\hline 0.2 & 0.174 & 1.455 & 0.000 & 0.0000 & 0.0434 & 0.0430 \\
\hline 0.25 & 0.202 & 1.444 & 2.328 & 0.0093 & 0.0396 & 0.0395 \\
\hline 0.3 & 0.229 & 1.433 & 4.655 & 0.0185 & 0.0358 & 0.0370 \\
\hline 0.4 & 0.275 & 1.412 & 9.363 & 0.0367 & 0.0294 & 0.0344 \\
\hline 0.5 & 0.312 & 1.361 & 13.948 & 0.0527 & 0.0240 & 0.0305 \\
\hline 0.6 & 0.337 & 1.285 & 18.378 & 0.0656 & 0.0191 & 0.0247 \\
\hline 0.7 & 0.347 & 1.200 & 22.747 & 0.0758 & 0.0146 & 0.0199 \\
\hline 0.8 & 0.334 & 1.112 & 27.145 & 0.0838 & 0.0105 & 0.0161 \\
\hline 0.9 & 0.280 & 1.027 & 31.575 & 0.0901 & 0.0067 & 0.0134 \\
\hline 0.95 & 0.210 & 0.985 & 33.788 & 0.0924 & 0.0048 & 0.0140 \\
\hline 1.0 & 0.000 & 0.942 & 36.000 & 0.0942 & 0.0029 & 0.0000 \\
\hline
\end{tabular}

computed from the lifting surface analysis are validated with experiments given in [21] as shown in Figures 2, 3, 4 and 5, respectively. The agreement between the results of analysis and experiments is satisfactorily good. For all propellers, the maximum efficiency about $\mathrm{J}=1$ has the same value except DTMB 4382 model propeller which has a slightly lower efficiency under open water and noncavitating conditions.

Table 3. Main Dimensions of DTMB 4383 Propeller

\begin{tabular}{|l|l|l|l|l|l|l|}
\hline $\mathrm{r} / \mathrm{R}$ & $\mathrm{c} / \mathrm{D}$ & $\mathrm{P} / \mathrm{D}$ & $\begin{array}{l}\text { Skew } \\
{ }^{0} \mathrm{f}\end{array}$ & $\mathrm{Rk} / \mathrm{D}$ & $\mathrm{t}_{\max } / \mathrm{D}$ & $\mathrm{f}_{\max } / \mathrm{c}$ \\
\hline 0.2 & 0.174 & 1.566 & 0.000 & 0 & 0.0434 & 0.0402 \\
\hline 0.25 & 0.202 & 1.539 & 4.647 & 0 & 0.0396 & 0.0408 \\
\hline 0.3 & 0.229 & 1.512 & 9.293 & 0 & 0.0358 & 0.0407 \\
\hline 0.4 & 0.275 & 1.459 & 18.816 & 0 & 0.0294 & 0.0385 \\
\hline 0.5 & 0.312 & 1.386 & 27.991 & 0 & 0.0240 & 0.0342 \\
\hline 0.6 & 0.337 & 1.296 & 36.770 & 0 & 0.0191 & 0.0281 \\
\hline 0.7 & 0.347 & 1.198 & 45.453 & 0 & 0.0146 & 0.0230 \\
\hline 0.8 & 0.334 & 1.096 & 54.245 & 0 & 0.0105 & 0.0189 \\
\hline 0.9 & 0.280 & 0.996 & 63.102 & 0 & 0.0067 & 0.0159 \\
\hline 0.95 & 0.210 & 0.945 & 67.531 & 0 & 0.0048 & 0.0168 \\
\hline 1.0 & 0.000 & 0.895 & 72.000 & 0 & 0.0029 & 0.0000 \\
\hline
\end{tabular}

Table 4. Main Dimensions of DTMB 4384 Propeller

\begin{tabular}{|l|l|l|l|l|l|l|}
\hline $\mathrm{r} / \mathrm{R}$ & $\mathrm{c} / \mathrm{D}$ & $\mathrm{P} / \mathrm{D}$ & $\begin{array}{l}\text { Skew } \\
\left({ }^{0}\right)\end{array}$ & $\mathrm{Rk} / \mathrm{D}$ & $\mathrm{t}_{\max } / \mathrm{D}$ & $\mathrm{f}_{\max } / \mathrm{c}$ \\
\hline 0.2 & 0.174 & 1.675 & 0.000 & 0.0000 & 0.0434 & 0.0545 \\
\hline 0.25 & 0.202 & 1.629 & 6.961 & 0.0315 & 0.0396 & 0.0506 \\
\hline 0.3 & 0.229 & 1.584 & 13.921 & 0.0612 & 0.0358 & 0.0479 \\
\hline 0.4 & 0.275 & 1.496 & 28.426 & 0.1181 & 0.0294 & 0.0453 \\
\hline 0.5 & 0.312 & 1.406 & 42.152 & 0.1646 & 0.0240 & 0.0401 \\
\hline 0.6 & 0.337 & 1.305 & 55.199 & 0.2001 & 0.0191 & 0.0334 \\
\hline 0.7 & 0.347 & 1.199 & 68.098 & 0.2269 & 0.0146 & 0.0278 \\
\hline 0.8 & 0.334 & 1.086 & 81.283 & 0.2453 & 0.0105 & 0.0232 \\
\hline 0.9 & 0.280 & 0.973 & 94.624 & 0.2557 & 0.0067 & 0.0193 \\
\hline 0.95 & 0.210 & 0.916 & 101.300 & 0.2578 & 0.0048 & 0.0201 \\
\hline 1.0 & 0.000 & 0.859 & 108.000 & 0.2578 & 0.0029 & 0.0000 \\
\hline
\end{tabular}




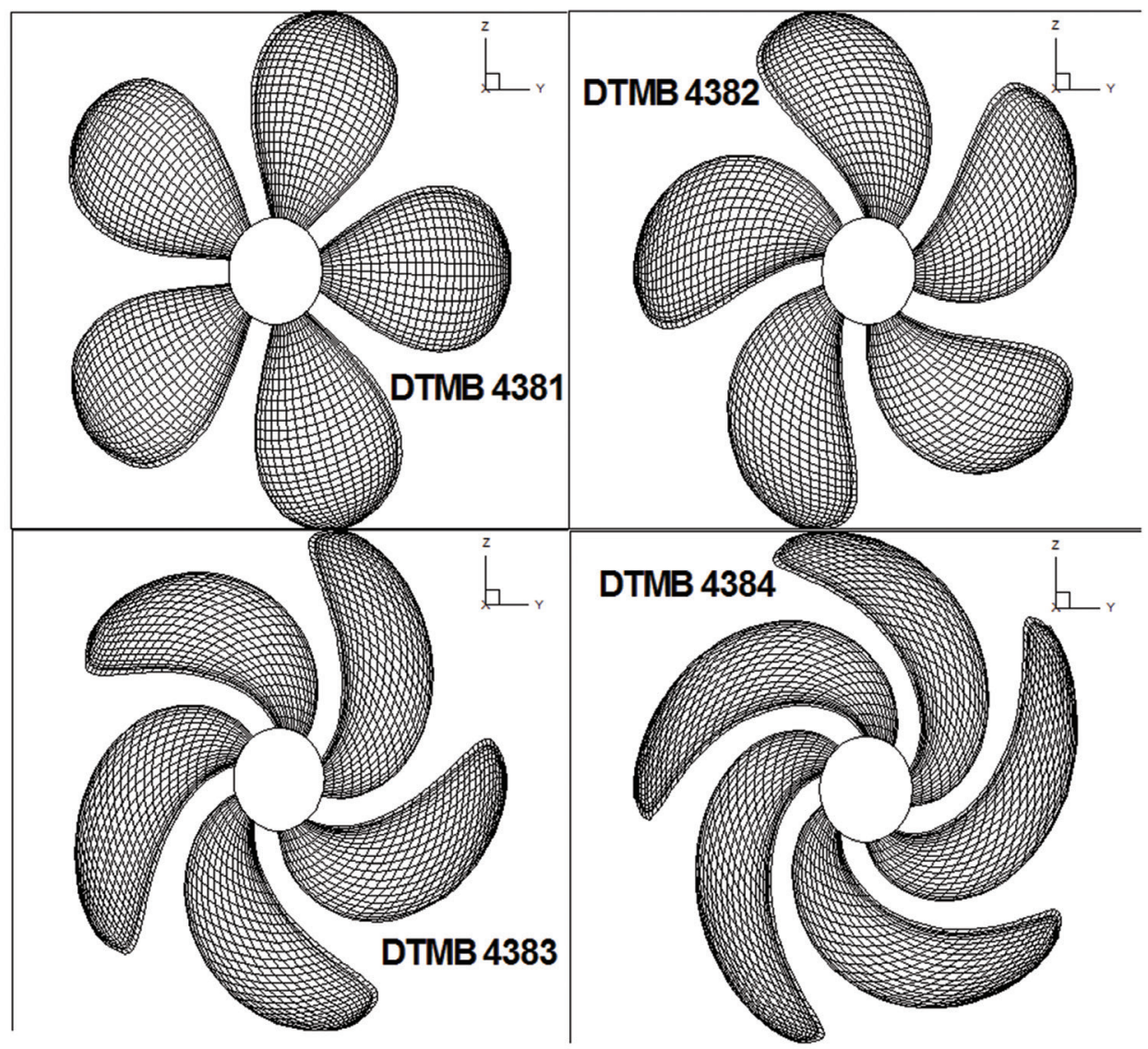

Figure 1. Front Views and Panels of Four Propellers

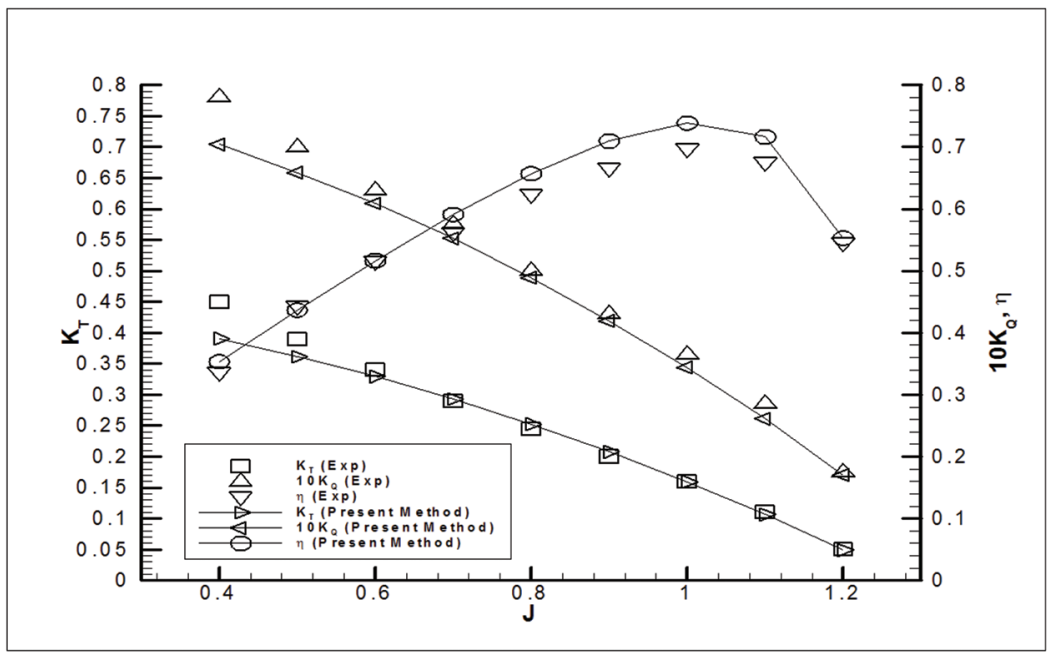

Figure 2. Comparison of Open Water Results with Experiment (DTMB 4381) 


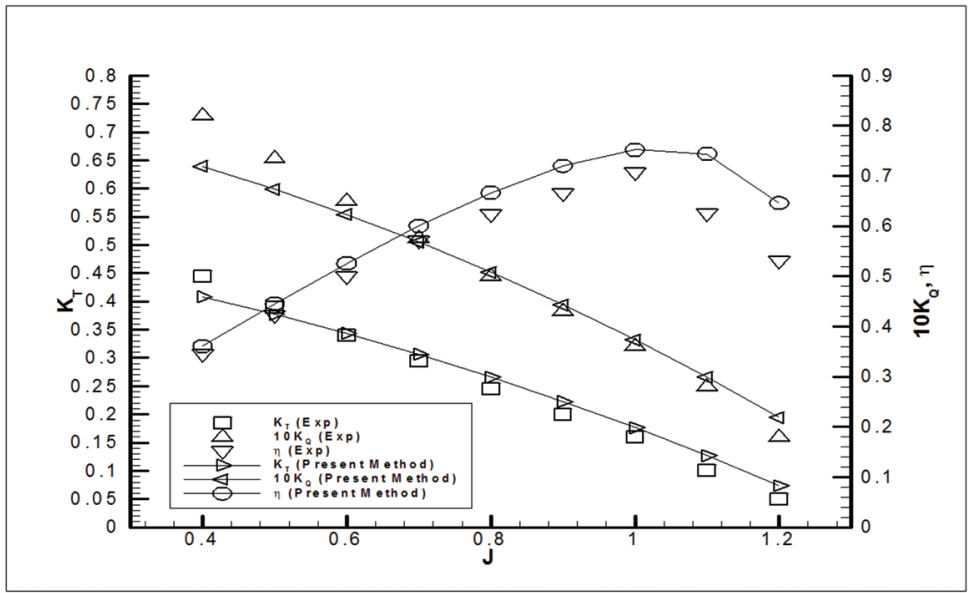

Figure 3. Comparison of Open Water Results with Experiment (DTMB 4382)

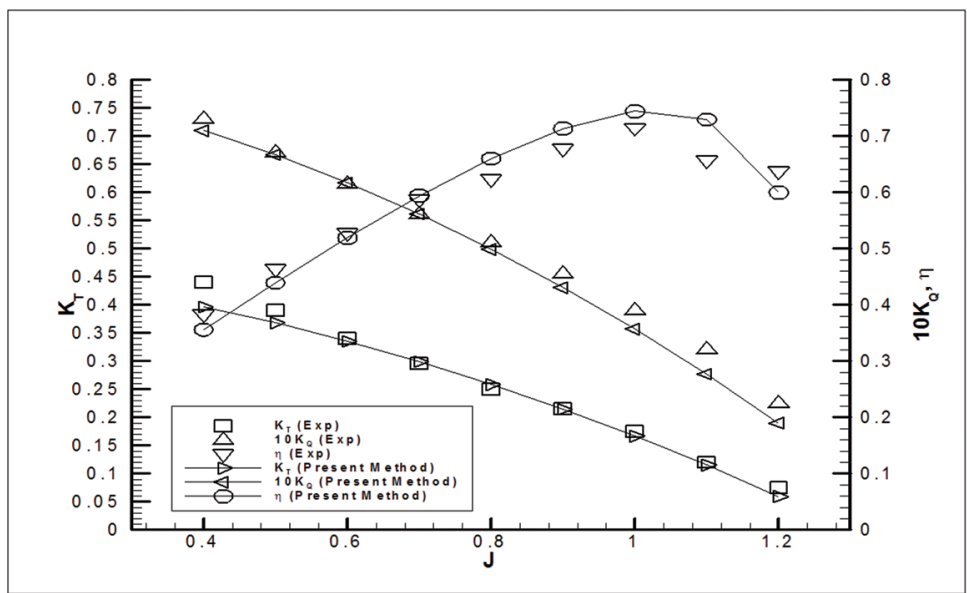

Figure 4. Comparison of Open Water Results with Experiment (DTMB 4383)

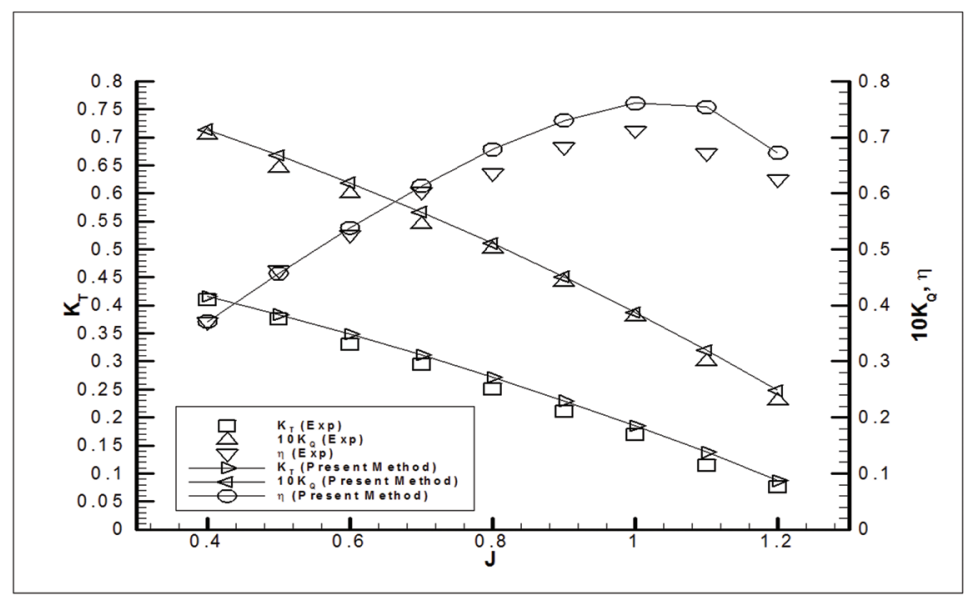

Figure 5. Comparison of Open Water Results with Experiment (DTMB 4384) 
Later, the lifting surface method is applied to cavitating DTMB 4381 and 4382 propellers for validation. The advance coefficient is selected as $\mathrm{J}=0.7$ and the cavitation number $\sigma=1.715$ for validation under cavitating conditions [21]. The non-dimensional cavitation number is defined as:

$$
\sigma=\frac{p-p_{V}}{\frac{1}{2} \rho(n D)^{2}}
$$

Here, $p$ is the static pressure on the shaft axis of propeller, $\mathrm{pV}$ is the vaporize pressure of water. $\rho$ is the density of water, $\mathrm{n}$ is the revolution speed (revolution per second) and D is the diameter of propellers. The computed cavity patterns $(J=0.7$ and $\sigma=1.715)$ by present method are compared with experiments [21] for DTMB 4381 and 4382 propellers as shown in Figures 6 and 7, respectively. Note that the agreement between two is satisfactory for practical engineering applications except near very local region around mid-radius of DTMB 4381 model propeller. The tip vortex cavity has also been captured very well for both propellers.

Then, the lifting surface method is applied to all cavitating propellers (DTMB 4381, 4382, 4383 and 4384). The advance coefficient is first assumed to be $\mathrm{J}=0.8$ (low loading on propeller) and the cavitation number is $\sigma=1.9$. The computed cavity patterns by present method are shown for four propellers as shown in Figure 8. Note that the cavity area is almost the same for all propellers. It does not change with a skew angle. The only difference for this case (low loading condition on propeller) is that tip vortex cavity is starting to develop with an increase in skew angle. The advance coefficient is later assumed to be $\mathrm{J}=0.4$ (higher loading on propeller) and the cavitation number is $\sigma=2.9$. The computed cavity patterns by present method are shown for four propellers as shown in Figure 9. Note that the cavity area is now reducing for propellers which have increasing skew angles. Note also for this case (higher loading condition on propeller) that tip vortex cavity is starting to develop much larger than the previous case, with an increase in skew angle.
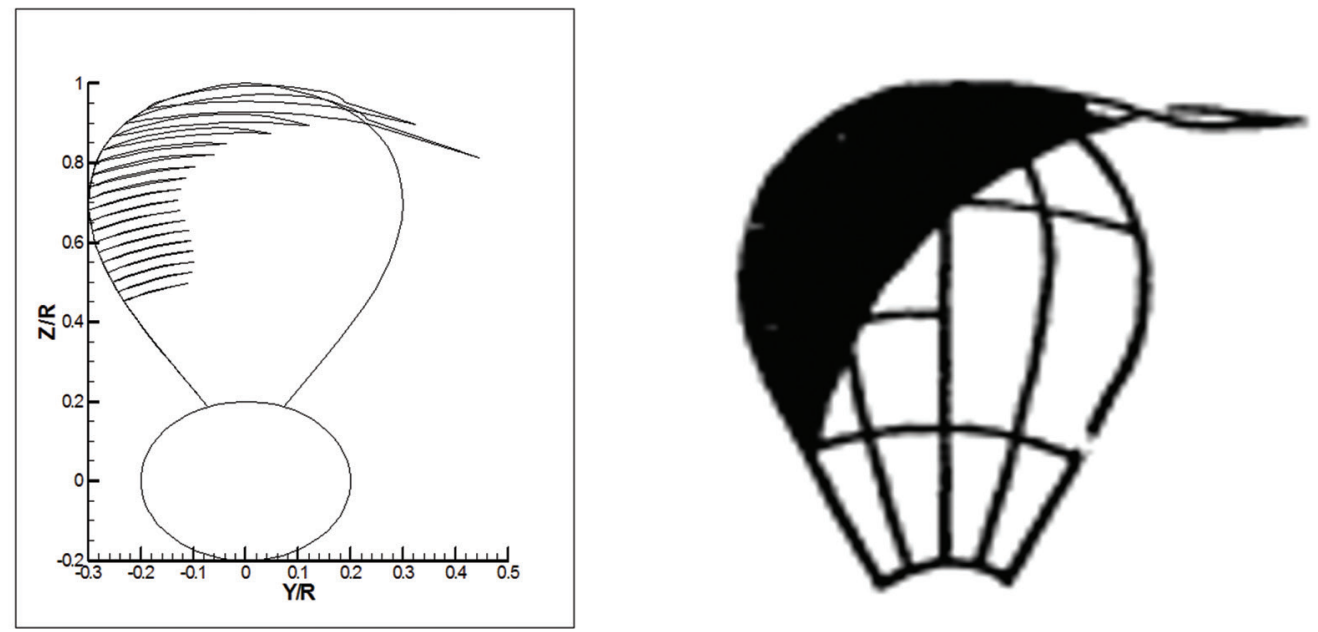

Figure 6. Comparison of Cavity Pattern with Experiments, $J=0.7, \sigma=1.715$ (DTMB 4381) (Left: Present Method, Right: Experiment taken from [21]) 

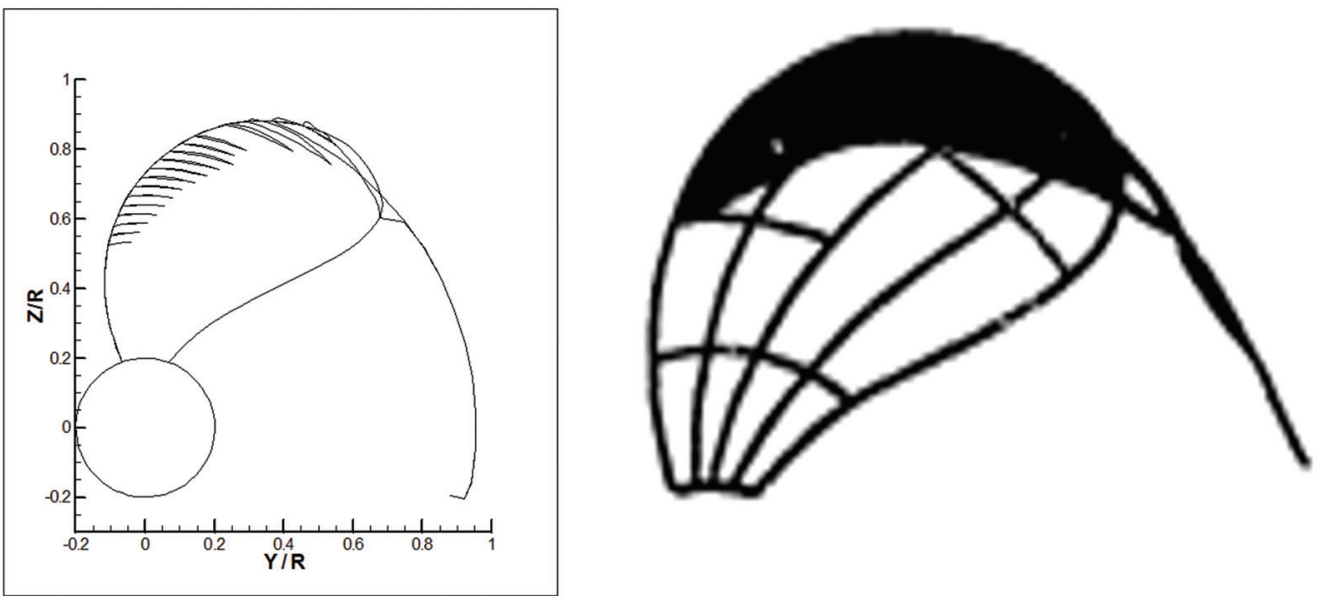

Figure 7. Comparison of Cavity Pattern with Experiments, J=0.7, $\sigma=1.715$ (DTMB 4382) (Left: Present Method, Right: Experiment taken from [21])

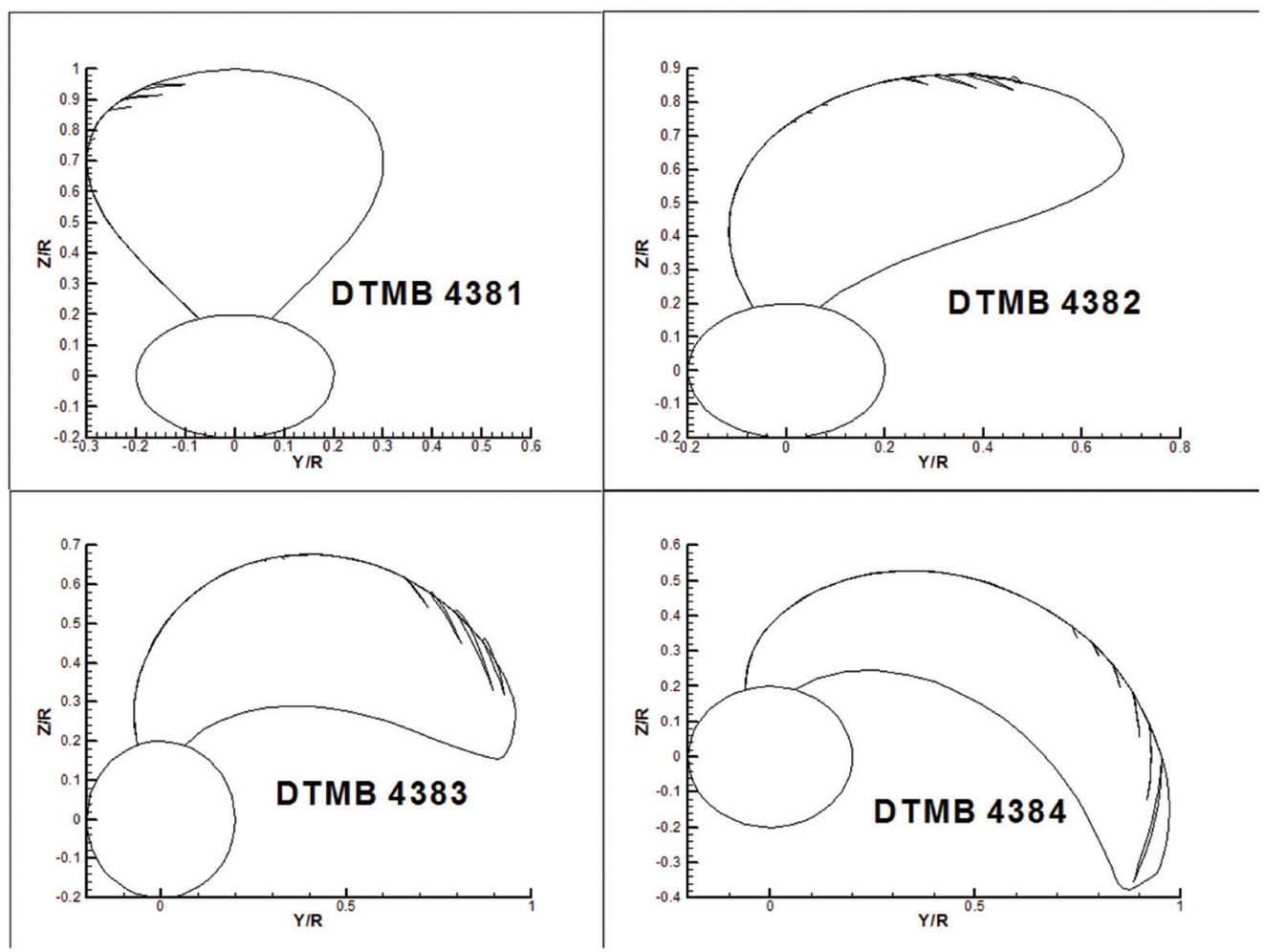

Figure 8. Cavity Patterns of Four Propellers for J=0.8, $\sigma=1.9$ 


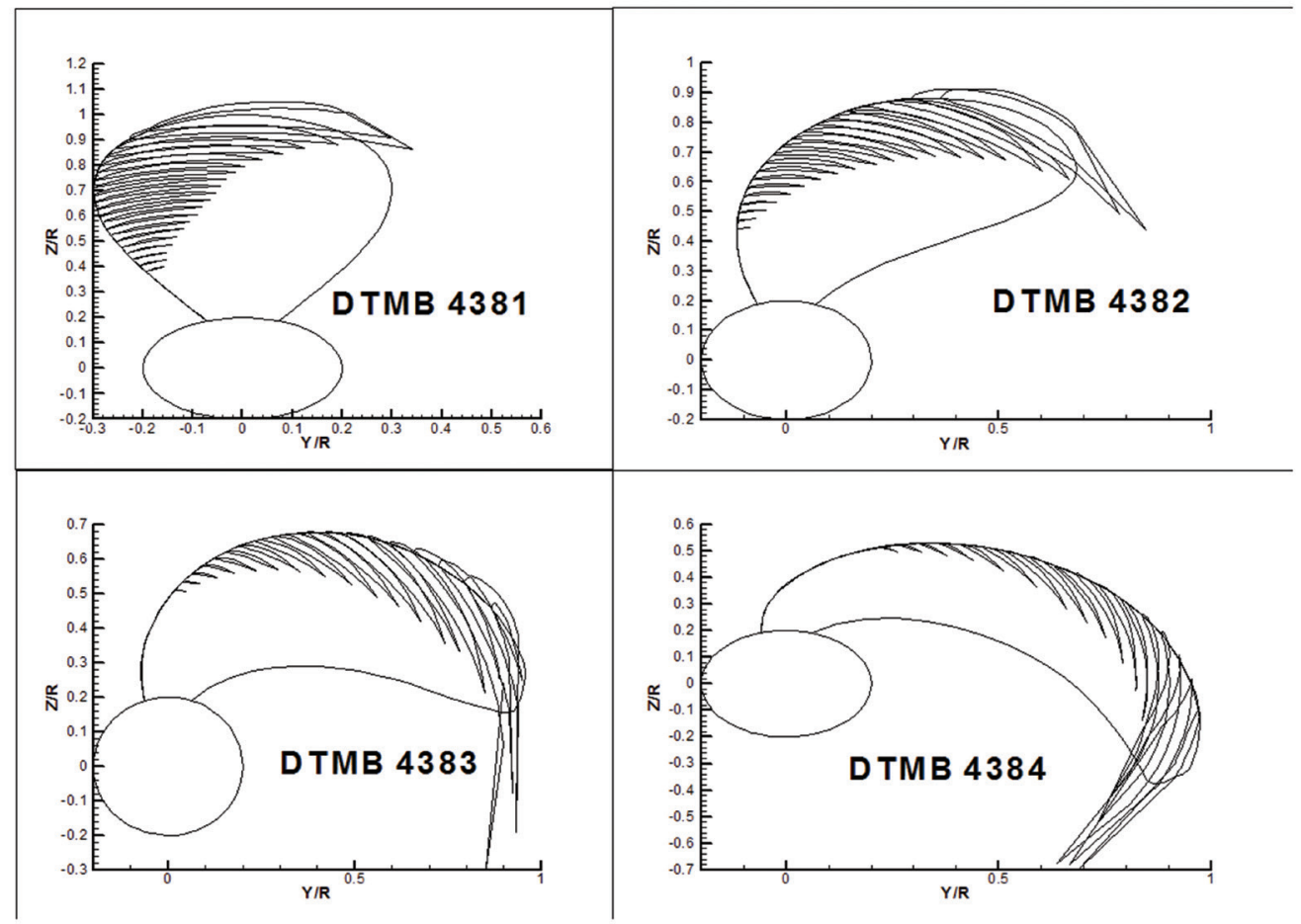

Figure 9. Cavity Patterns of Four Propellers for J $=0.4, \sigma=2.9$

\section{Conclusions}

In this study, the skew influence on cavitation has been investigated by a lifting surface method. It has been found that all four propellers (DTMB 4381, 4382, 4383 and 4384) under noncavitating conditions have almost the same maximum efficiency values between the given range of advance coefficients except DTMB 4382 propeller. This propeller has a slightly lower maximum efficiency value. On the other hand, under cavitating conditions, the skew has a positive effect for higher loading conditions. Higher skew angle causes lower cavity area and thus volume. For lower loading conditions, skew does not matter anymore.

\section{References}

[1] Hu, J., Huang, Q., Guo, T., Geng, C. and Sun, S. (2017). Cavitation simulation of highly skewed propellers. 2nd International Conference on Architectural Engineering and New Materials (ICAENM 2017), Feb. 2526, Guangzhou, China, 218-226.

[2] Zhu, Z.F. (2013). Numerical study of the effect of propellers skew on cavitation performance. Advanced Materials Research, Vol. 705: 405409.

[3] Ji, B., Luo, X., Wang, X., Peng, X., Wu, Y. and $\mathrm{Xu}, \mathrm{H}$. (2011). Unsteady numerical simulation of cavitating turbulent flow around a highly skewed model marine propeller. Journal of Fluids Engineering, Vol. 133: 011102011102-8. doi:10.1115/1.4003355.

[4] Wang, L.Z., Guo, C.Y., Su, Y.M and Wu, T.C. (2018). A numerical study on the correlation between the evolution of propeller trailing vortex wake and skew of propellers. International journal of Naval Architecture and Ocean Engineering, 10: 212-224. 
[5] Zhu, Z.F. (2015). Numerical study on characterisitc correlation between cavitating flow and skew of ship propellers. Ocean Engineering, 99: 63-71.

[6] Ghasseni, H. and Ghadimi, P. (2011). Numerical analysis of the high skew propeller of an underwater vehicle. Journal of Marine Science and Application, 10 (3): 289e299.

[7] Baek, D.G., Yoon, H.S., Jung, J.H., Kim, S.K. and Paik, B.G. (2015). Effects of the advance ratio on the evolution of a propeller wake. Computers and Fluids, 118: 32-43.

[8] Bal, S. (2010). Hydrodynamic performance of ship propellers. Shipyard, No: 17: 32-36.

[9] Kerwin, J.E. and Lee, C-S. (1978). Prediction of steady and unsteady marine propeller performance by numerical lifting-surface theory. Trans. SNAME, 86.

[10] Lee, C-S. (1979). Prediction of steady and unsteady performance of marine propellers with or without cavitation by numerical lifting surface theory, PhD thesis, M.I.T., Department of Ocean Engineering, USA.

[11] Kinnas, S.A., Griffin, P., Choi, J-K. and Kosal, E. (1998). Automated design of propulsor blades for high-speed ocean vehicle applications. Trans. SNAME, 106.

[12] Greeley, D.S. and Kerwin, J.E. (1982). Numerical methods for propeller design and analysis in steady flow. Trans. SNAME, 90.

[13] Szantyr, J.A. (1994). A Method for analysis of cavitating marine propellers in non-uniform flow. International Shipbuilding Progress, 41: 223-242.

[14] Celik, F. and Guner, M. (2006). Improved lifting line method for marine propeller. Marine Technology, SNAME, 43: 100-113.
[15] Bal, S. and Guner, M. (2009). Performance analysis of podded propulsors. Ocean Engineering, 36: 556-563.

[16] Bal, S. (2011). A method for optimum cavitating ship propellers. Turkish Journal of Engineering and Environmental Sciences, 35:139158.

[17] Bal, S. (2011). A practical technique for improvement of open water propeller performance. Proceedings of the Institution of Mechanical Engineers, Part M, Journal of Engineering for the Maritime Environment, 225: 375-386.

[18] Griffin, P.E. and Kinnas, S.A. (1998). A design method for high-speed propulsor blades. Journal of Fluids Engineering, 120: 556-562.

[19] Kerwin, J.E. (2001). Hydrofoils and propellers. Lecture Notes, Department of Ocean Engineering, Massachusettes Institute Technology, USA.

[20] Carlton, J.S. (2012). Marine propellers and propulsion. Oxford: Elsevier (Butterworth-Heinmann) Publ.

[21] Boswell, R.J. (1971). Design, cavitation performance and open water performance of a seriesof research skewed propellers. NSRDC Report No: 3339, USA.

[22] Brizzolara, S., Villa, D. and Gaggero, S. (2008). A systematic comparison between RANS and panel methods for propeller analysis. Proc. of 8th International Conference on Hydrodynamics, Nantes, France, Sep. 30-Oct. 3. 